\title{
Interrelations among children, parents, premedication, and anaesthetists in paediatric day stay surgery
}

\author{
N McC Schofield, J B White
}

\begin{abstract}
Objective-To investigate the incidence of difficulties associated with parental presence during the induction of anaesthesia in children and the influence of premedication with special reference to vomiting after papaveretum.
\end{abstract}

Design-Mixed factual and multiple choice questionnaire completed by medical and nursing staff and parents during and after admission.

Setting-Teaching hospital with regional paediatric general surgical unit where parental presence during induction of anaesthesia is long established.

Patients-151 Children aged 1-14 years who had not previously undergone surgery attending with parents for day stay general surgical procedures.

Intervention-Children were randomly allocated to receive no premedication (group 1), oral diazepam elixir ( $0.3 \mathrm{mg} / \mathrm{kg}$ ) (group 2), or intramuscular papaveretum with hyoscine $(0.3 \mathrm{mg} / \mathrm{kg}$ with $0.006 \mathrm{mg} / \mathrm{kg})$ (group 3). No other modification to established day stay routine was made.

Results-No major problems were associated with the presence of parents during the induction of anaesthesia. Only 10 of the 141 parents who accompanied their child caused some difficulty, and five became distressed. Premedication with both diazepam and papaveretum resulted in sedation but did not ease induction of anaesthesia. Papaveretum greatly reduced pain and distress immediately after the operation, pain and discomfort being observed in only $15 \%$ of children $(7 / 48)$ compared with $66 \%$ $(27 / 41)$ in group 1 and $49 \%(22 / 45)$ in group 2 . Papaveretum, however, must be given intramuscularly, and nurses observed that the children preferred being given premedication orally to intramuscularly. In addition, the incidences of nausea and vomiting were significantly higher in the postoperative ward and at home with papaveretum, although no patient who had been given the drug was nauseous or vomited in the recovery area. The incidences of nausea in group 3 were $62 \%(31 / 50)$ and $57 \%(27 / 47)$ in the postoperative ward and at home, respectively, $v 21 \%(7 / 33)$ and $14 \%(4 / 29)$ in group 1 and $13 \%(5 / 38)$ and $14 \%(5 / 37)$ in group 2 ; the incidences of vomiting in group 3 were $60 \%$ and $43 \%$ in the postoperative ward and at home, respectively, $v 18 \%$ and $7 \%$ in group 1 and $11 \%$ and $11 \%$ in group 2 . Finally, neither the administration or otherwise of premedication nor the drug given affected the children's or parents' perception of day care surgery.

Conclusions-Difficulties with parents in anaesthetic rooms were not common or severe. Premedication provides preoperative sedation and papaveretum improves the immediate postoperative course but the incidences of nausea and vomiting after operation are higher with its use than without.

\section{Introduction}

Opinion among anaesthetists has long been divided on whether parents should be present in anaesthetic rooms. The subject received a great deal of attention in
1985 after Mr Adrian While's personal view was published in the $B M \mathcal{F} .^{1}$ He described his family's experiences during his $3 \frac{1}{2}$ year old daughter's admission for insertion of grommets. The anaesthetist was apparently adamant that there was no benefit in a parent being present during induction of anaesthesia and he would not anaesthetise if one did attend. The premedication did not work well, the father was angry and upset, and the child was terrified and screaming. Her first action when she awoke in the ward afterwards was to sit bolt upright and scream for help. She later had no recall of so doing but did have complete, vivid, and distressing memories of being held down and a mask forced on to her face to induce anaesthesia. $\mathrm{Mr}$ While felt that, whatever the anaesthetist's misgivings, the presence of a parent could not possibly have made things worse. The correspondence that followed ${ }^{2-13}$ and the responses in other journals ${ }^{14-16}$ illustrate many of the views held by anaesthetists and others and the strength of feelings on the subject.

Our study was prompted by difficulties that arose when some anaesthetists new to our unit found the presence of parents unsettling and tried, contrary to long established practice, to prevent them accompanying their children to the anaesthetic room. We also examined current premedication regimens in the unit after one of our surgical colleagues observed that several children had to stay overnight because of vomiting. ${ }^{1718}$

\section{Patients and methods}

The subjects were children aged from 1 to 14 years admitted for general surgical procedures as day patients. None of the children had previously been admitted to any hospital for a surgical procedure and their parents had not accompanied any child during a surgical admission to the unit where the study took place. The patients were admitted to the paediatric surgical ward by the surgical house officer after the operating list had started and the anaesthetist was contacted only if there was doubt about the fitness of the child for.anaesthesia. Day stay children's surgery is performed on operating lists normally undertaken or supervised by a consultant anaesthetist.

The children were assigned a number in the study in the order in which they were admitted to the ward and were randomly allocated to one of three premedication groups using tables that had been generated by a computer for the study. Group 1 was prescribed no premedication, group 2 oral diazepam elixir $(0.4 \mathrm{~g} / \mathrm{l}) 0.3 \mathrm{mg} / \mathrm{kg}$, and group 3 intramuscular papaveretum and hyoscine $(20 \mathrm{~g} / \mathrm{l}$ with $0.4 \mathrm{~g} / \mathrm{l})$ $0.3 \mathrm{mg} / \mathrm{kg}$ and $0.006 \mathrm{mg} / \mathrm{kg}$. Premedication was given one hour before surgery. Lignocaine and prilocaine cream for local surface anaesthesia (Emla) became available in the hospital only part way through this study and was not used. It was not considered ethical to give placebo preparations and so every effort was made to conceal the premedication used from the anaesthetist until assessment of induction of anaesthesia had been completed. The randomisation of premedication was the only modification made to the long established 
routine for children admitted for day case surgery, and no change was made to the agents prescribed. It was considered prudent, however, to obtain approval of the study by the district ethics committee, which was granted.

Letters were sent with the preadmission information to the parents explaining the study but avoiding giving additional information not normally available to them. Formal consent for inclusion in the trial was not obtained but parents could opt out. In addition, a letter was sent to each general practice in the catchment area giving rather more detail of the study in case the parents might wish to discuss it before admission.

Information was elicited by means of a questionnaire in six parts. The first four parts were completed in the hospital by the house surgeon and ward nurse before the operation, the anaesthetist in the anaesthetic room and operating theatre, the recovery nurse, and, again, the ward nurse after the operation. The fifth part was completed about two days after discharge by the parents and postage was prepaid. The last part had a blank form, without prepaid postage, to give the parents an opportunity to make comments about a month after the operation. The questions were of two types: those recording facts about patients or events and those in which an opinion was sought from the observer of each phase of the admission. The questions eliciting the opinion of the observers were designed to offer four options: good, satisfactory, less than satisfactory, and unacceptable. The questionnaire had a total of 106 questions, of which 39 elicited opinions.

All answers to the questionnaires were transferred on to computer at the Oxford University Computing Service by using the statistical analysis system (SAS 2) statistical package modified to accept and compute 24 hour times. The SAS 2 program includes various statistical tests and display formats. The tests used were one way analysis of variance for comparing means and standard deviations of demographic data and $\chi^{2}$, combining cells when expected frequencies were less than five, for non-parametric information from the multiple choice questions.

\section{Results}

Initially 160 children were included in the study. Nine were excluded from the analysis of results because the anaesthetist failed to complete part B of the questionnaire sufficiently fully, and a further seven

TABLE I-Demographic data on children in three premedication groups. Values are means $(S D)$ unless stated otherwise

\begin{tabular}{lccc}
\hline & $\begin{array}{c}\text { Group 1 } \\
(\mathbf{n}=48)\end{array}$ & $\begin{array}{c}\text { Group 2 } \\
(\mathbf{n}=45)\end{array}$ & $\begin{array}{c}\text { Group 3 } \\
(\mathrm{n}=51)\end{array}$ \\
\hline Age (years) & $5 \cdot 61(2 \cdot 87)$ & $5 \cdot 04(2 \cdot 77)$ & $4 \cdot 90(2 \cdot 73)$ \\
Weight (kg) & $20 \cdot 7(8 \cdot 2)$ & $18 \cdot 5(6 \cdot 3)$ & $18 \cdot 4(6 \cdot 7)$ \\
Sex $(M / F)$ & $46 / 2$ & $36 / 9$ & $45 / 6$ \\
No of siblings & $1 \cdot 28(0 \cdot 97)$ & $1 \cdot 27(0 \cdot 82)$ & $1 \cdot 46(0 \cdot 93)$ \\
No(\%) of only children & $7(16)$ & $7(16)$ & $4(8)$ \\
Mother's age (years) & $32 \cdot 8(5 \cdot 9)$ & $32 \cdot 5(5 \cdot 8)$ & $31 \cdot 6(4 \cdot 9)$ \\
Father's age (years) & $35 \cdot 0(6 \cdot 1)$ & $36 \cdot 2(5 \cdot 8)$ & $35 \cdot 0(5 \cdot 7)$ \\
Parent in anaesthetic room (\%): & & & \\
$\quad$ Mother & $36(75)$ & $37(82)$ & $39(76)$ \\
$\quad$ Father & $10(21)$ & $5(11)$ & $6(12)$ \\
\hline
\end{tabular}

TABLE II-Mean (SD) times (minutes) between main events during day stay admission and distances travelled $(\mathrm{km})$ in three premedication groups

\begin{tabular}{lccc}
\hline & Group 1 $(\mathrm{n}=48)$ & Group 2 $(\mathrm{n}=45)$ & Group 3 $(\mathrm{n}=51)$ \\
\hline Admission to premedication & N/A & $101(59)$ & $108(57)$ \\
Premedication to anaesthetic room & N/A & $59(30)$ & $61(28)$ \\
Anaesthetic room to induction & $7 \cdot 3(5 \cdot 3)$ & $7 \cdot 6(5 \cdot 8)$ & $8 \cdot 5(10 \cdot 4)$ \\
Induction to entering recovery room & $31(16)$ & $28(21)$ & $27(16)$ \\
Entering to leaving recovery room & $45(17)$ & $50(29)$ & $49(21)$ \\
Arrival in ward to ready for discharge & $186(76)$ & $180(66)$ & $216(89)$ \\
Ready to actual discharge & $73(65)$ & $78(55)$ & $81(64)$ \\
Discharge to arrival at home & $37(16)$ & $33(16)$ & $40(20)$ \\
Distance travelled to home & $20 \cdot 9(14 \cdot 0)$ & $19 \cdot 1(11 \cdot 4)$ & $22 \cdot 4(14 \cdot 8)$ \\
\hline
\end{tabular}

TABLE III - Degree of sedation observed in anaesthetic room in each premedication group. Values are numbers (percentages) of patients

\begin{tabular}{lccc}
\hline & Group $1^{\star}(\mathrm{n}=48)$ & Group 2(n=45) & Group 3(n=51) \\
\hline Asleep & $3(6)$ & & $2(4)$ \\
Drowsy & $14(29)$ & $11(25)$ & $16(31)$ \\
Fairly alert & $31(65)$ & $15(33)$ & $23(45)$ \\
Very alert & $19(42)$ & $10(20)$ \\
\hline
\end{tabular}

${ }^{\star} \mathrm{p}<0.001$.

TABLE IV-Numbers (percentages) of anaesthetic and surgical procedures in each premedication group

\begin{tabular}{lrrr}
\hline & $\begin{array}{c}\text { Group 1 } \\
(\mathbf{n}=48)\end{array}$ & $\begin{array}{c}\text { Group 2 } \\
(\mathrm{n}=45)\end{array}$ & $\begin{array}{r}\text { Group 3 } \\
(\mathrm{n}=51)\end{array}$ \\
\hline $\begin{array}{l}\text { Induction technique: } \\
\quad \text { Intravenous }\end{array}$ & $37(77)$ & $34(76)$ & $36(71)$ \\
$\quad \begin{array}{l}\text { Inhalation } \\
\text { Operations performed: }\end{array}$ & $10(21)$ & $10(22)$ & $15(29)$ \\
$\quad$ Circumcision & $17(35)$ & $21(47)$ & $21(41)$ \\
$\quad$ Preputial adhesions & $2(4)$ & $2(4)$ & $4(8)$ \\
$\quad$ Inguinal & $17(35)$ & $11(24)$ & $18(35)$ \\
$\quad$ Rectal & $1(2)$ & $3(7)$ & $1(2)$ \\
$\quad$ Cystoscopy & $1(2)$ & $1(2)$ & \\
$\quad$ Laparoscopy & $3(6)$ & $4(9)$ & $3(6)$ \\
$\quad$ Abdominal wall & $1(2)$ & $4(9)$ & $4(8)$ \\
$\quad$ Other & $6(13)$ & $3(7)$ & $41(80)$ \\
Local anaesthetic blocks & $40(83)$ & $33(73)$ & \\
\hline
\end{tabular}

were excluded from the analysis of effects associated with premedication as they were assigned to receive premedication but did not do so. Of the 151 children whose results were analysed, the parents returned 142 (94\%) part E questionnaires.

Table I shows demographic details of the children in the three premedication groups. The only statistical difference was that children in group 3 had more parents from social class IV $(\mathrm{C} 2)^{19}(\mathbf{p}<0 \cdot 05)$.

The children were admitted between 830 and 9 am except for 16 who were scheduled to arrive by 11 am for late morning surgery. The times between main events during the day stay admission are given in table II. There were no significant differences among the premedication groups.

Most children were accompanied to the hospital by their mothers (108) or by both parents (30). Eleven fathers brought their children and two were accompanied by other relatives. After surgery 98 of the children travelled home by private car or taxi with an adult free to supervise them and 42 went home with only one adult, who was the driver.

\section{PREMEDICATION AND ANAESTHESIA}

No differences were observed during the clerking at admission in the emotional state of the children allocated to the three premedication groups. Nearly all the parents were helpful to the nurses and children during premedication. The nurses' opinions showed that oral premedication was clearly more acceptable to the children than that given intramuscularly $(\mathrm{p}<0.001)$, but difficulties in administration occurred in only six cases.

Table III shows the degree of sedation observed in the anaesthetic room in each group of children. Those who were not given premedication were more alert $(p<0.001)$. The groups showed no difference in the degree of apprehension in the anaesthetic room, the degree of difficulty of induction of anaesthesia, or the amount of distress caused to the child during induction. Most of the children (122/146) were completely or reasonably cooperative during induction of anaesthesia. Sixteen children were very apprehensive in the anaesthetic room and four others almost unmanageable. Twelve of the 20 had distressing inductions, their mothers accompanying all but three of them.

There were no differences in anaesthetic technique between the groups. In most cases anaesthesia was 
TABL.F V-Percentages (proportions) of children considered to be suffering from discomfort or pain a different times. Children in groups 1 and 2 who received narcotic analgesics at any time were excluded

\begin{tabular}{|c|c|c|c|c|c|}
\hline & & $\begin{array}{l}\text { Arrival in } \\
\text { recovery area }\end{array}$ & $\begin{array}{l}\text { Arrival in } \\
\text { postoperative ward }\end{array}$ & $\begin{array}{l}\text { Arrival } \\
\text { home }\end{array}$ & $\begin{array}{c}\text { First postoperative } \\
\text { morning }\end{array}$ \\
\hline Group 1 & $\left\{\begin{array}{l}\text { Discomfort only } \\
\text { Moderate or severe pain }\end{array}\right.$ & $\begin{array}{l}44(18 / 41) \\
29(12 / 41)\end{array}$ & $\begin{array}{rr}21 & (7 / 33) \\
6 & (2 / 33)\end{array}$ & $\begin{array}{l}38(11 / 29) \\
41(12 / 29)\end{array}$ & $\begin{array}{l}36(10 / 28) \\
50(14 / 28)\end{array}$ \\
\hline Group 2 & $\left\{\begin{array}{l}\text { Discomfort only } \\
\text { Moderate or severe pain }\end{array}\right.$ & $\begin{array}{l}20(9 / 45) \\
29(13 / 45)\end{array}$ & $\begin{aligned} 24 & (9 / 37) \\
5 & (2 / 37)\end{aligned}$ & $\begin{array}{l}41(15 / 37) \\
41(15 / 37)\end{array}$ & $\begin{array}{l}32(12 / 37) \\
43(16 / 37)\end{array}$ \\
\hline Group 3 & $\left\{\begin{array}{l}\text { Discomfort only } \\
\text { Moderate or severe pain }\end{array}\right.$ & $\begin{aligned} 13 & (6 / 48) \\
2 & (1 / 48)^{\star}\end{aligned}$ & $6(3 / 50)^{\star}$ & $\begin{array}{l}39(18 / 46) \\
28(13 / 46)\end{array}$ & $\begin{array}{l}37(17 / 46) \\
48(22 / 46)\end{array}$ \\
\hline
\end{tabular}

${ }^{\star} \mathrm{p}<0 \cdot 001$

induced intravenously with thiopentone sodium (mean dose $6 \cdot 12 \mathrm{mg} / \mathrm{kg}(\mathrm{SD} 1 \cdot 30)$ ) and the remainder were nearly all induced with oxygen, nitrous oxide, and halothane (table IV). The induction technique did not affect the children's cooperation during induction, the number who became distressed, or how the parents perceived their child's response to induction. Nitrous oxide, oxygen, and halothane were used to maintain anaesthesia in all but eight children, who were evenly distributed between the groups. There was no difference between groups in the incidence of minor anaesthetic difficulties (16\%), most of which were related to coughing and the production of excessive saliva.

The surgical procedures performed are summarised in table IV. Local or regional anaesthetic blockade with bupivacaine $0 \cdot 25 \%$ or $0.5 \%$ without adrenaline was widely used when appropriate.

\section{PAIN AND ANALGESIA}

The proportions of children who were thought to be uncomfortable or in moderate or severe pain on awakening are shown in table $\mathrm{V}$. Children from groups 1 and 2 who were given narcotic analgesics as part of their anaesthetic were excluded. The table also shows the different observers' assessments of pain at later stages and that children in group 3 seemed to be much more comfortable until after their return to the ward $(p<0.001)$. The greater comfort of all groups of children on arrival in the ward may be because more local blocks become effective, the most distressed children were given narcotic analgesia in the recovery room, or the children were reunited with parents.

Forty nine children became distressed in the recovery room from causes considered by the nurse to be other than or in addition to pain. Disorientation (16 patients), separation from parents (31), and unfamiliarity with surroundings (14) were regarded as the most common causes. Only three of these children were in group 3 , most being evenly distributed

TABLE VI-Incidences of nausea and vomiting in each group at different times. Children in groups 1 and 2 who received supplementary narcotic analgesics were excluded. Values are percentages (proportions)

\begin{tabular}{|c|c|c|c|c|}
\hline & & $\begin{array}{c}\text { Recovery } \\
\text { area }\end{array}$ & $\begin{array}{c}\text { Postoperative } \\
\text { ward }\end{array}$ & Home \\
\hline Group 1 & $\left\{\begin{array}{l}\text { Nausea } \\
\text { Vomited }\end{array}\right.$ & $\begin{array}{l}16(7 / 42) \\
12(5 / 42)\end{array}$ & $\begin{array}{ll}21 & (7 / 33) \\
18 & (6 / 33)\end{array}$ & $\begin{array}{rr}14 & (4 / 29) \\
7 & (2 / 29)\end{array}$ \\
\hline Group 2 & $\left\{\begin{array}{l}\text { Nausea } \\
\text { Vomited }\end{array}\right.$ & $\begin{array}{l}7(3 / 45) \\
4(2 / 45)\end{array}$ & $\begin{array}{ll}13 & (5 / 38) \\
11 & (4 / 38)\end{array}$ & $\begin{array}{ll}14 & (5 / 37) \\
11 & (4 / 37)\end{array}$ \\
\hline Group 3 & $\left\{\begin{array}{l}\text { Nausea } \\
\text { Vomited }\end{array}\right.$ & & $\begin{array}{l}62(31 / 50)^{\star} \\
60(30 / 50)\end{array}$ & $\begin{array}{l}57(27 / 47)^{\star} \\
43(20 / 47)\end{array}$ \\
\hline
\end{tabular}

${ }^{\star} \mathrm{p}<0 \cdot 001$.

TABLE VII - Parents' and children's responses to aspects of day stay surgery. Results are parents' assessmen of events. Values are percentages (proportions)

\begin{tabular}{lcccc}
\hline & $\begin{array}{c}\text { Child's } \\
\text { overall opinion }\end{array}$ & $\begin{array}{c}\text { Parents' } \\
\text { overall opinion }\end{array}$ & $\begin{array}{c}\text { Parent's anaesthetic room } \\
\text { experience }\end{array}$ & $\begin{array}{c}\text { Child's opinion of } \\
\text { anaesthetic induction }\end{array}$ \\
\hline Enjoyable or happy & $10(15 / 141)$ & $6(9 / 142)$ & $16(21 / 131)$ & $39(52 / 132)$ \\
Reasonably pleasant & $48(67 / 141)$ & $58(83 / 142)$ & $60(79 / 131)$ & $33(44 / 132)$ \\
A little unpleasant & $35(49 / 141)$ & $28(39 / 142)$ & $21(27 / 131)$ & $18(23 / 132)$ \\
Unpleasant or distressing & $7(10 / 141)$ & $8(11 / 142)$ & $3(4 / 131)$ & $10(13 / 132)$
\end{tabular}

between the two other groups. Paracetamol elixir was administered equally to patients in all groups before discharge $(24 \%, 36 / 151)$ and at home $(68 \%$, $97 / 143)$. The administration of oral analgesia to children who were being sick caused difficulty to parents.

\section{NAUSEA AND VOMITING}

Table VI shows the incidences of nausea and vomiting at different times. It excludes those who received narcotic analgesics as part of the anaesthetic technique or for analgesia in the recovery area. Nine children remained in hospital overnight. In four of these vomiting was a major contributory factor, although three others were also sick. Minor surgical complications kept four in hospital and one was monitored for an unexplained tachycardia.

More than half of the children $(55 \%, 21 / 38)$ who were sick after leaving hospital vomited during the journey home. At the end of the questionnaire parents were asked how upset they thought that their child was by being sick. There were no differences between premedication groups and overall, out of 134 replies, 20 thought that their child was not upset at all and 71 that he or she was a little upset, 38 quite upset, and five very upset.

\section{PARENTS AND ANAESTHETIC ROOM}

A ward nurse accompanied the child and parents to the operating theatre suite reception area. One parent continued with the child into the anaesthetic room (table I) while the nurse returned to the ward. Ten children were unaccompanied by either a parent or relative in the anaesthetic room.

Five of the 141 parents who came to the anaesthetic rooms were obviously anxious. Two of these became distressed and two others were tearful, but no parent needed to be accompanied from the anaesthetic room. Only six parents were considered to be unhelpful to the child in the anaesthetic room and none caused major difficulty. Ten parents were less than helpful to the anaesthetist, but only one was disruptive as she was very distressed. Her child slept through the preinduction period and had an uneventful induction of anaesthesia. No parent was obviously unwell during his or her visit to the theatre suite. Ten parents failed to leave immediately when they were asked to do so, but no problems arose. Usually the delay was to give the child a last kiss or because the parent was unsure what was expected of him or her.

The anaesthetists thought that they established good or adequate rapport with all but six parents and 15 children in the anaesthetic room. There was no relation between achievement of rapport with parent and with child.

Table VII summarises the children's and parents' opinions of their attendance for day stay surgery both overall and in the anaesthetic room. There were no differences between premedication groups in the responses to these questions. No parent thought that they were in any way unhelpful to their child in the anaesthetic room. Most parents (124 out of 139) thought that they had received sufficient or almost sufficient information before admission and three quarters of them (110) tried to tell their child as much as they could about going into hospital. Only 18 parents told their child little or nothing.

All parents who were present in the anaesthetic room thought that their child wanted them to be present or that their presence would help the child. Only a quarter (32) thought that they had also responded to outside influences such as television, magazines, or relatives' opinions. Ten parents would not have attended had they not thought that it would help their 
TABLE VIII - Aspects of study that showed no statistical evidence of differences among three premedication groups

Helpfulness of parents to nurse and child during premedication

Degree of:

Anxiety of child on arrival in anaesthetic room and of parent in anaesthetic room

Cooperation of child during induction of anaesthetic Child's and paren's distress during induction of ands and paren

Helpfulness of parents to anaesthetists and child in anduess of parent

anaesthetic room

Rapport established between anaesthetist and paren Anaesthetist's opinion of smoothness of induction of anaesthesia

Incidence of minor unexpected incidents during anaesthesia

Level of consciousness of child on arrival in recovery area

nalgesia administered postoperatively in surgical ward before discharge
Parents' overall opinion of day stay surgery (recorded before leaving hospital and two or more days later) Child's first night's sleep at home

Pain on:

Arrival home

First postoperative morning at home

Analgesia requirements at home

Parents' assessment of child's opinion of day stay surgery

Parent's opinion of:

Pleasantness or otherwise of being in anaesthetic room

Child's response to method of induction of

anaesthesia

Effect of his or her presence on child during

induction of anaesthesia

Distress caused to child by being sick

child. Anxiety was the main reason for parents electing not to accompany a child.

Only 25 blank forms without prepaid postage (part $F$ of the questionnaire) were returned. Sixteen gave information of unsatisfactory aspects of the day and nine were positive in that the experience had been better than anticipated. Two children had become frightened of hospitals and one had had an asthma attack for the first time six days after the operation. Eight complaints related to cicumcision-mostly about not knowing what to expect-and eight others complained of lack of general information leading to distress and inconvenience for the parents.

Table VIII summarises the aspects of this study in which no correlation was found between answers to multiple choice questions and the premedication group to which the child belonged.

\section{Discussion}

The low incidence of any difficulties with parents in the anaesthetic room (7\%) is encouraging, as is the small number (five, $4 \%$ ) of parents who were clearly distressed..$^{20}$ Better preoperative information about the activities and routine in the anaesthetic room may reduce these problems and also the occasional delays in parents leaving when indicated. Many anaesthetists observed that some parents seemed to take no part in events while in the anaesthetic room, but they did not cause any difficulty. The parents all thought themselves helpful in the anaesthetic room.

In the unit where the study took place the anaesthetists were unable to visit day stay patients preoperatively for logistical reasons. Even so, adequate or good rapport was established with most children and parents in the anaesthetic room. Many of the letters in response to $\mathrm{Mr}$ While's personal view recommend preoperative visits, ${ }^{346}$ and, though this study gives no indications that large improvements would result from such visits, many anaesthetists would prefer to make them. More information could then be given to parents and children about events in the anaesthetic room and theatre suite and the likely postoperative difficulties of the different operations, and the anaesthetists could discuss with anxious parents whether they should accompany their child.

Views on the use of premedication are strongly held and differ widely. ${ }^{11} 16^{22-24}$ In our study premedication with papaveretum and hyoscine greatly reduced pain and distress during the immediate postoperative recovery phase but at the price of intramuscular administration $^{2425}$ and increased vomiting. ${ }^{18}$ The vomiting was an important factor in only four of the nine children who were admitted overnight, but it was most inconvenient during the journey home for many children and parents. Both diazepam and papaveretum with hyoscine caused noticeable sedation in the

anaesthetic room ${ }^{26}$ but premedication did not affect the ease of induction of anaesthesia (K C Hickmott et al, annual scientific meeting of the Association of Paediatric Anaesthetists of Great Britain and Ireland, Sheffield, 1986). ${ }^{26}$ Moreover, it did not affect the children's or parents' perception of their day in hospital. ${ }^{20}$

When children were considered to be upset in the recovery room from causes other than pain, separation, particularly from parents, and disorientation and unfamiliarity with their surroundings were regarded as the main reasons. Several parents commented that they or their child had wished that the parent could have been present during awakening. The logistics of permitting parents to be present in a busy, mixed general recovery area make such provision extremely difficult. A solution might be to create a dedicated paediatric day case theatre and recovery area with facilities and sufficient recovery staff to allow parents to be present. ${ }^{27}$ Children should be moved from the recovery area as soon as they are sufficiently alert to minimise separation in unfamiliar surroundings.

The purpose of the part $F$ of the questionnaire, which did not have prepaid postage, was to provide motivated parents with an opportunity to pass on late information. It is encouraging that only $11 \%$ of parents took this opportunity to make adverse comments and that nearly all of these comments were related to lack of information, ${ }^{28}$ especially about the postoperative course of circumcision. It is regrettable that two children became frightened of hospitals and one had a first asthma attack six days after admission, but this low incidence of problems is likely to be difficult to improve on. No other long term effects were reported (K C Hickmott et al, annual scientific meeting of the Association of Paediatric Anaesthetists of Great Britain and Ireland, Sheffield, 1986), ${ }^{26}$ and only $6 \%$ (nine) had more than minor sleep disturbances on the first postoperative night.

This study should encourage anaesthetists that a parent's presence does not generate many problems in the anaesthetic room. No assessment of the benefits of their presence could be made, but other studies have shown that there are benefits $(\mathrm{K} \mathrm{C}$ Hickmott et al, annual scientific meeting of the Association of Paediatric Anaesthetists of Great Britain and Ireland, Sheffield, 1986), ${ }^{2021}$ except perhaps when the parents are particularly anxious. ${ }^{27}$ It is important to provide adequate information to the parents, ${ }^{28}$ both about events during the day and about the likely course after the operation. Premedication remains a personal choice of the anaesthetist, depending on his or her opinion of the importance of anaesthetic room sedation and immediate postoperative comfort when compared with the special problems of vomiting in day case patients.

This study was supported by a grant from the Oxfordshire District Health Authority Research Fund. We thank Mrs Caroline Fordham for her help in preparing the original questionnaires, Miss Teresa Bahu for typing, and Miss Jean Holderness for distributing the circular letters. Miss Su Dyson's help in entering the data into the SAS program was invaluable as was the data processing by $\mathrm{Mr}$ Christopher Pierce, director of the University Data Centre, Nuffield Department of Medicine, John Radcliffe Hospital, Oxford. Finally, thanks to Mrs Katie Whipp and Tricia John for typing the manuscript.

1 While A. Personal view. Br Med f 1985;291:343.

2 Black GW, Bush GH, Morris P. Paediatric anaesthesia. $\mathrm{Br}$ Med $f$ 1985;291:542.

3 Dev VJ. Paediatric anaesthesia. Br Med f 1985;291:542.

4 Catling J, Lindsay WA, Radford P, Rooms M. Paediatric anaesthesia. BrMed f 1985:291:543.

5 Kilpatrick S. Paediatric anaesthesia. Br Med f 1985;291:543.

6 Gell IR, Harris RW. Paediatric anaesthesia. Br Med f 1985;291:543.

6 Gell IR, Harris RW. Paediatric anaesthesia. Br Med f 1985;291:5

8 Roberts WO. Paediatric anaesthesia. Br.Med f 1985;291:543. 
9 Holt S. Paediatric anaesthesia. Br.Med f 1985;291:673.

10 Fisher NGS, Armitage EN, Williams PAP. Paediatric anaesthesia. Br Med f $1985 ; 291: 673$

11 Carter AJ. Paediatric anaesthesia. Br. Med 7 1985;291:824.

12 Lask B. Paediatric anaesthesia. Br Med f 1985:291:824.

13 While A Paediatric anaesthesia. Br Med 7 1985;291:824.

14 Anonymous. Parents in the anaesthetic room [Editorial]. Lancet 1986;ii:903.

15 Davenport HT, Valman B. Parents in the anaesthetic room. Lance 1987;i:45-6.

16 Carter AJ Premedication for children Anaesthesia 1986;41:440.

17 Booker PD, Chapman DH. Premedication in children undergoing day care surgerv. Br f Anaesth 1979;51:1083-7.

18 Keneally JP. Day stay surgery in paediatrics. Clinics in Anaesthesiolog 1985;3:679-95

9 Thompson EJ, ed. Social trends 10. London: HMSO, 1980:290-1.

20 Hannallah RS, Rosales JK. Experience with parents' presence during anaesthesia induction in children. Canadian Anaesthetists Society fournal 1983;30:286-9
21 Schulman JL, Foley JM, Vernon DTA, Allan D. A study of the effect of the mother's presence during anesthesia induction. Pediatrics 1967;39:111-4. Jago RH. Induction of anaesthesia in children. Anaesthesia 1986:41:885.

23 Steward DJ. Anaesthesia for paediatric outpatients. Canadiun Anaesthetists Society Journal 1980;27:4126.

4 Johnson GG. Day case surgery for infants and children. Canadian Anaesthetists Society foumal 1983;30:553-7.

25 Jones SEF, Smith BAC. Anesthesia for pediatric day-surgery. F Pediatr Surg 1980;15:31-3.

26 Padfield NL, Twonig MMcD, Frazer ACL. Temazepam and trimeprazine compared with placebo as premedication in children. $\mathrm{Br} f$ Anaesth $1986 ; 58: 487-93$

27 Johnston CL, Bevan JL, Haig MJ, Kirnon V, Tousignant G. Parental presence during anesthesia induction. AORN $\mathcal{F}$ 1988;47:186-94.

28 Cohen D, Keneally J, Black A, Gaffrey S, Johnson A. Experience with day surgery. F Pediatr Surg 1980;15:21-5.

(Accepted 4 October 1989)

\title{
Effect of a training programme to reduce stress in carers of patients with dementia
}

\author{
H Brodaty, Meredith Gresham
}

\section{Abstract}

Objective-To reduce the psychological stress and improve the skills in coping of people who care for relatives with dementia.

Design-Assessment and suitability of carers by questionnaire; assessment of patients and carers in a hospital outpatient clinic; allocation to groups according to date of application to study. Linkage of groups of four carers and programme coordinator by telephone conference calls over 12 months after programmes. Reassessment at three, six, 12, and, for those in the "wait list" group, 18 months.

Setting-The programmes were conducted in the psychiatry unit of a Sydney teaching hospital.

Subjects-Eligible patients were less than 80 years old, had mild to moderate dementia, and lived at home with their carer. Of the 96 patient-carer pairs in the study, 33 were in the dementia carers' programme group, 31 were in the memory retraining group, and 32 were in the wait list group.

Interventions-Carers in the dementia carers' programme received training in coping with the difficulties of looking after patients with dementia while the patients had sessions in subjects such as memory retraining. In the memory retraining programme patients were admitted and received the patient component of the carers' programme while their carers had 10 days' respite. In the wait list group carers waited six months before undertaking the carers' programme.

Main outcome measures-Effect of the programmes on carers' general health questionnaire scores and the rate of placement of patients in institutions.

Results-At 12 months' follow up the carers' programme had resulted in significantly lower psychological stress among carers than the memory retraining programme (mean (SD) general health questionnaire scores at 0 months were $6.31(6.23)$ and $3.60(6.25)$ respectively, and at 12 months were $4.69(5.58)$ and $7.40(9.39) ; p<0.05$.) In the wait list group distress scores remained stable, even after the carers and patients had undertaken the carers' programme. Patients deteriorated over 12 months regardless of group allocation, but at $\mathbf{3 0}$ months, allowing for patients who died and could not be included in the analysis, $65 \%$ of patients in the carers' programme group were still living at home compared with $26 \%$ in the memory retraining programme group.

Conclusion-The intensive intervention pro- gramme described for carers of patients with dementia can reduce the psychological morbidity of the carer and delay the placement of the patient in an institution without increasing the use of health services by either patient or carer.

\section{Introduction}

Dementia is an unremitting burden' that leads to the carers of people with the condition becoming demoralised,,$^{2}$ isolated, ${ }^{3}$ and psychologically distressed..$^{3-6}$ Interventions to ease the plight of carers are needed, but empirical studies of such interventions have been sparse.

Intervention techniques have included attempts to enhance carers' skills in coping by cognitive behavioural approaches, training in problem solving, and educational therapy $^{6.9}$; meditative relaxation ${ }^{679}$; training in social skills ${ }^{5610}$; supportive counselling of individuals and groups or families, or both ${ }^{810}$; and management of stress. "The following outcomes were reported: reduced family burden ${ }^{810}$; decreased psychological morbidity ${ }^{10}$; increase in carers' knowledge about dementia $^{10}$; and increased assertiveness and tolerance. ${ }^{9}$ But these studies have various limitations: they comprised small numbers of subjects ${ }^{679}$; there was no follow up $^{6-810}$; interventions were limited ${ }^{(6-1)}$; there was a "floor effect" of low psychological morbidity of carers before training"; and the outcome of patients was not evaluated. ${ }^{6-11}$

We sought to overcome these methodological difficulties by designing an intervention programme for carers living at home with a relative with dementia. Our aim was to reduce distress and improve the quality of life for both patients and carers and to reduce the rate of placement of patients in institutions. In designing a package of appropriate interventions we took into account factors known to influence .carers' psychological distress. ${ }^{3}$ We reasoned that if we could modify these factors we would enhance our ability to reduce carers' psychological morbidity. We designed the dementia carers' programme, a highly structured 10 day residential training programme for patients and carers but aimed principally at carers and evaluated it against two control interventions.

Subjects and methods

SUBJECTS

Subjects were recruited by referral or publicity. Of the 96 carers, 40 indicated that they had entered the 